\title{
Estratégia de Manufatura e Ambiente Econômico: Comparando Desempenhos e Trajetórias de Brasil e Argentina
}

\author{
Paulo Fernando Fleury \\ Rebecca Arkader
}

RESUMO

O objetivo deste trabalho é buscar indicações sobre a existência de relações entre ambiente econômico e estratégia de manufatura, baseado na comparação de empresas argentinas e brasileiras pertencentes ao setor metalmecânico. Mais especificamente, se pretende identificar similaridades e diferenças nas trajetórias de modernização adotadas por empresas de cada país e discutir possíveis explicações para o comportamento das empresas em condições de forte mudanças no ambiente econômico. Diferenças históricas e estruturais, assim como o clima econômico dominante na época da pesquisa, parecem ter influenciado as empresas argentinas no sentido de busca uma modernização mais centrada nos investimentos tecnológicos - hardware, enquanto as empresas brasileiras se concentravam nas mudanças de software, ou seja, nos procedimentos e práticas gerenciais associados ao modelo conhecido como manufatura enxuta. Por ter começado mais cedo, e por ter partido de uma base mais fraca de desempenho, as melhorias relativas relativas de desempenho conseguidas pelas empresas argentinas, nos dois anos que antecederam a pesquisa, foram superiores àquelas alcançadas pelas empresas brasileiras.

Palavras-chaves: estratégia de manufatura, trajetórias de modernização, desempenho comparado.

\section{ABSTRACT}

The objective of this paper is to look for indications of possible relationships between economic environment and manufacturing strategy, based on a comparison of Brazilian and Argentinean firms belonging to the metal products, machinery, and equipment industry. More specifically, it is our intention to identify similarities and differences in the modernization paths followed by companies of both countries, and also to discuss possible explanations for the behavior of companies in a period of significant changes in the economic environment. Structural and historical differences, as well as the prevailing economic environment by the time of the research seem to have influenced Argentinean companies in the direction of a more technological based modernization path - investments in hardware. Brazilian companies, on the other side, have concentrated their modernization efforts in the software side, i. e. in changing management practices towards a lean manufacturing model. During biennial period previous to this research, Argentinean companies achieved superior relative improvements in performance, when compared to their Brazilian counterparts, probably because they started earlier and from a weaker performance base.

Key words: manufacturing strategy, modernization paths, comparative performance. 


\section{NTRODUÇ ̃̃O}

Brasil e Argentina representam, respectivamente, a primeira e a terceira maior economia da América Latina. Ambos os países são membros atuantes do Mercosul, e passaram nos últimos anos por consideráveis mudanças no seu ambiente econômico, caracterizadas pela adoção de planos de estabilização, de privatização e abertura econômica. Embora semelhantes em vários aspectos, as mudanças na Argentina foram feitas há mais tempo do que no Brasil, e portanto, os resultados apresentam defasagem temporal, quando se comparam os dois países.

Desde 1990, uma série de medidas vem sendo tomadas no Brasil, com o objetivo de reduzir o alto grau de protecionismo e reduzir a presença do Estado na economia, mediante programas de desregulamentação e privatização. No entanto as medidas que causaram maior impacto sobre a economia, ou seja aquelas voltadas para debelar o processo desenfreado de inflação que vinha assolando o país por mais de uma década, só ocorreram em meados de 1994, com a introdução do plano Real. Na Argentina, por outro lado, o plano de estabilização baseado na garantia de conversibilidade da moeda, já havia sido implementado cerca de 3 anos antes. Apesar das diferenças entre os dois planos, as empresas em ambos os países foram forçadas a adotar novos procedimentos administrativos, pois ficaram expostas a uma competição muito mais vigorosa, tanto por parte dos importados quanto por parte das empresas instaladas localmente.

Embora as empresas brasileiras tenham enfrentado sérias dificuldades durante a década de 80, na Argentina os efeitos da instabilidade econômica e de uma recessão prolongada foram muito mais devastadores. Embora ambos os países tenham passado por longo período de situações adversas, nas vésperas da virada econômica a situação da Argentina era certamente de desvantagem em relação ao Brasil, no que diz respeito aos aspectos estruturais e infra-estruturais da atividade industrial.

O esforço de pesquisa do IMSS ${ }^{(1)}$ conseguiu montar uma ampla base de dados sobre as estruturas, práticas, e estratégias de manufatura - atuais e planejadas de cerca de 600 empresas industriais (dos setores de metalurgia, máquinas e equipamentos industriais), situadas em 20 diferentes países, localizados em 4 diferentes continentes (América do Norte, América do Sul, Europa, e Ásia). Os dados foram coletados em 1993 e, portanto, refletem diferentes momentos do processo de transição de uma economia fechada para um economia mais aberta ao comércio internacional, tanto no Brasil quanto na Argentina. As empresas brasileiras, embora seriamente pressionadas pela crise daquele momento, estavam 
aparentemente melhor equipadas, com base na sua experiência anterior, a enfrentar o novo ambiente competitivo. As empresas argentinas, por outro lado, estavam beneficiando-se de ambiente econômico muito mais propício aos negócios, que se caracterizava por um clima altamente positivo de crescimento de demanda e investimentos.

Confrontadas em ambos os países com a necessidade de se prepararem para uma competição mais acirrada no início dos anos 90 , as empresas tinham diante de si as alternativas de realizar mudanças na sua tecnologia de produção hardware, ou nos processos de gestão - software, ou em ambos, com o objetivo de se manterem competitivas no novo ambiente econômico. No caso do hardware isto significaria mudança nas antigas instalações, ou construção de novas com a utilização de equipamentos mais modernos e mais automatizados; em termos de software significaria a adoção de programas e procedimentos identificados com o novo paradigma de gestão da produção conhecido como "manufatura enxuta" ${ }^{\prime \prime}$.

O objetivo deste trabalho é buscar indicações sobre a existência de relações entre ambiente econômico e estratégia de manufatura, baseado na comparação de dados de empresas argentinas e brasileiras que compõem a amostra do IMSS. Mais especificamente, se pretende identificar similaridades e diferenças nas trajetórias de modernização adotadas por empresas de cada país e discutir possíveis explicações para o comportamento das empresas em condições de fortes mudanças no ambiente econômico.

Após uma apresentação sumária, na seção 2, de alguns indicadores que ajudam a entender o ambiente de negócios em cada país em 1993, a seção 3 mostra alguns dados comparativos das empresas: suas estruturas operacionais e desempenhos, seus planos de melhorias, os programas de modernização adotados, e os resultados obtidos. A seção 4 discute as semelhanças e diferenças identificadas, assim como as possíveis razões explicativas para tal. O trabalho se encerra com uma tentativa de caracterizar as trajetórias de modernização em cada país, buscando ao mesmo tempo entender quais as implicações destas trajetórias para a competitividade futura das empresas argentinas e brasileiras, em face do novo ambiente internacional de negócios que deverá predominar na segunda metade dos anos 90 .

\section{As Economias de Argentina e Brasil segundo os dados de $1993^{(3)}$}

A economia brasileira, a oitava maior do mundo em termos de PIB, era $60 \%$ maior do que a argentina em 1993 (com PIBs respectivamente de US\$ 409 e 
US\$ 260 bilhões). Em termos de renda per capita, por outro lado, a Argentina possuía uma situação bem superior a do Brasil - US\$ 7.760, comparada com US\$ 2.618. Naquele ano, os efeitos do plano de estabilização já podiam ser observados na Argentina, onde a taxa de crescimento do PIB para o período entre 1989 e 1993 foi de 5,85\%, comparados com um valor negativo de 0,08\% no Brasil. Ambos os países tiveram decréscimo no crescimento da produção industrial em 1992, relativamente a 1980: o número índice para o Brasil foi de 0,95, enquanto o da Argentina foi de 0,99 $(1980=1,00)$.

Os dados de inflação para 1993 são ainda mais desfavoráveis para a economia brasileira: uma extraordinária taxa anual de $2.830 \%$ comparada com apenas $10,6 \%$ na Argentina depois do plano de estabilização. Mas a aparente resistência da economia brasileira tinha como suporte seus melhores resultados no comércio exterior: exportações quase três vezes maior (US\$ 39,9 contra US\$ 14,4 bilhões), correspondendo a uma maior parcela do PIB. Mais significativo ainda é a taxa de crescimento das exportações no período 1990-92: 6,55\% comparado com um valor negativo de $0,75 \%$ : a balança de pagamentos era positiva em US\$12,85 bilhões no Brasil, comparada com um déficit de US\$ 3,71 bilhões na Argenti$\mathrm{na}^{(4)}$.

Os dados sobre investimentos externos mostram o efeito do plano de estabilização sobre os níveis de investimentos na Argentina: os investimentos externos diretos foram de US $\$ 4,18$ bilhões comparados com apenas US $\$ 1,45$ bilhões no Brasil. As razões para tal discrepância podem estar nas opiniões expressas pelos executivos, na pesquisa realizada para o World Competitiveness Report do IMD, sobre aspectos como controle de preços, participação direta do Estado na produção, leis antitruste e proteção à propriedade intelectual: em todos estes itens a Argentina obteve melhor avaliação do que o Brasil. Esta também foi a situação no que se refere ao custo de capital e investimentos em infra-estrutura. $\mathrm{O}$ sistema de distribuição física foi um dos poucos aspectos onde o Brasil foi melhor desempenho do que a Argentina.

O Brasil também estava em pior situação no que diz respeito ao índice de analfabetismo. De fato, as opiniões dos executivos sobre a disponibilidade de mão de obra qualificada nos dois países, favorecia também a Argentina. O oposto no entanto ocorria quando a avaliação era sobre a disponibilidade de gerentes senior, e de engenheiros qualificados, assim como sobre a rotatividade da mão de obra.

A produtividade da mão de obra na Argentina era substancialmente maior: US\$ 10,23 contra US\$ 3,78 por empregado hora, ou US\$ 11,477 contra US\$ 8,118 por pessoa empregada ${ }^{(5)}$. O índice de variação na produtividade global no período 1985-1993 foi negativo para as duas nações, mas a Argentina com um 
índice de $-2,9 \%$ teve um desempenho pior do que o Brasil, com - $0,61 \%$. O rendimento por hora de trabalho na indústria manufatureira Argentina era superior à do Brasil, ou seja, US\$3,30, comparado com US\$ 2,55.

\section{Comparando as Estratégias de Manufatura na Argentina E NO BRASIL}

\section{Perfil das Empresas Entrevistadas}

As subamostras brasileira e argentina que compõem a base de dados do IMSS são respectivamente de 28 e 41 empresas pertencentes aos setores de produtos metálicos, máquinas e equipamentos industriais. As empresas de ambos os países são líderes de mercado nos segmentos de sua principal linha de produtos; $47 \%$ contra $30 \%$ do competidor mais próximo no caso da Argentina, e 40\% contra $21 \%$ no caso brasileiro. Estes número parecem indicar que, pelo menos no caso dos subsetores industriais considerados, o mercado argentino era mais concentrado que o brasileiro; entretanto os mercados para as principais linhas de produtos na Argentina estavam em franca expansão, enquanto no Brasil eles eram considerados estáveis.

Existiam também fortes similaridades entre as empresas dos dois países em relação ao foco geográfico e de mercado/cliente. No que diz respeito ao primeiro, ambos os países classificaram a intensidade de foco na faixa mediana da escala 1 a 5; as percentagens dos produtos exportados também eram similares; $23 \%$ na Argentina e $28 \%$ no Brasil, assim como a percentagem dos insumos importados, respectivamente de $31 \%$ e $29 \%$. No que diz respeito ao foco de clientes, numa escala de 1 (poucos clientes) a 5 (muitos clientes) os scores eram praticamente os mesmos; 3,4 e 3,3 respectivamente para as empresas argentinas e brasileiras.

Outro ponto de similaridade era que a maioria das empresas na Argentina e no Brasil adotavam preferencialmente o sistema de produção por pedidos, em contraposição ao sistema baseado em previsões e produção para estoque. Existia no entanto maior incidência de tal prática nas empresas brasileiras (77\%), quando comparado com as empresas argentinas (64\%).

Em contraposição às similaridades, várias diferenças foram observadas entre as empresas dos dois países. O tamanho das empresas se destaca como uma das maiores diferenças, sendo que as empresas brasileiras eram bem maiores do que as argentinas. Na média elas tinham quase cinco vezes mais empregados 
(1.476 versus 300 ), 80\% mais máquinas e equipamentos (182 versus 107), e maior número de fábricas ( $46 \%$ das empresas brasileiras tinham mais de uma fábrica, comparados com apenas $26 \%$ das empresas argentinas).

A questão da integração vertical também distinguia as duas subamostras. As empresas argentinas tendiam a uma maior verticalização, ou seja, enquanto $69 \%$ do seu valor agregado advinha das atividades de fabricação, contra $31 \%$ das atividades de montagem, no caso do Brasil os números eram 54\% para fabricação contra $46 \%$ para montagem.

As políticas de capacidade pareciam ser mais agressivas na Argentina do que no Brasil; $41 \%$ das empresas argentinas adotavam um colchão positivo de capacidade (investiam em excesso de capacidade) e $44 \%$ planejavam sua capacidade para se equilibrar com a demanda, enquanto no Brasil os mesmos números eram $21 \%$ e $71 \%$ respectivamente.

As empresas argentinas e brasileiras também se distinguiam uma das outras na forma como organizavam sua produção. Sessenta e um por cento das argentinas adotavam sistema de produção em lotes, 30\% usavam linha de produção e $8 \%$ produção unitária. No caso do Brasil a adoção dos 3 sistemas era mais balanceado. A produção unitária assim como a produção por lotes eram utilizadas por $35 \%$ das empresas, enquanto as restantes $30 \%$ se utilizavam do sistema de linhas de produção.

As estruturas de custos também eram razoavelmente diferentes entre as empresas dos dois países. Os salários diretos representavam maior parcela no custo de produção das empresas argentinas, $26 \%$, contra apenas $20 \%$ no caso do Brasil. A participação dos materiais nos custos de produção eram maiores no Brasil do que na Argentina, ou seja, $57 \%$ comparados com $48 \%$.

\section{Desempenho Operacional das Empresas}

Uma comparação entre as empresas argentinas e brasileiras, em termos de desempenho operacional, indica que as últimas tinham melhor desempenho em termos de eficiência no uso de recursos (tanto materiais quanto humanos), enquanto as primeiras mostravam uma superioridade nas variáveis relacionadas com diferenciação/serviços (velocidade de entrega, e inovatividade). No entanto, empresas de ambos os países estavam, em geral, muito atrás das melhores práticas internacionais de manufatura.

A maior eficiência no uso de recursos, no caso das empresas brasileiras, foi verificada por meio de quatro variáveis operacionais: giro de estoques, duas 
vezes maior do que na Argentina (7,4 versus 3,7); rotatividade da mão de obra, quase a metade da média das empresas argentinas (3,9 versus 7,3); absenteísmo, quase a metade do índice argentino ( $2,4 \%$ versus $4,4 \%)$; e eficiência produtiva (throughput efficiency), quase $40 \%$ superior no Brasil (68\% versus 49\%).

Maior capacidade de diferenciação, no caso das empresas argentinas, foi verificada pela análise de 3 indicadores: prazo total de entrega (37 dias comparados com 99 dias no caso das empresas brasileiras); investimentos em pesquisa e desenvolvimento $(4,5 \%$ das receitas versus $3,9 \%$ no caso das empresas brasileiras); e percentual da receita total advinda de novos produtos $(20 \%$ na Argentina versus $11 \%$ no Brasil).

Em ambos os países as empresas apresentavam deficiência substancial no que diz respeito a um importante aspecto social da manufatura: o número de sugestões por empregado-ano. Enquanto a média de todas as 600 empresas participantes da pesquisa IMSS foi de 7,6, os números para Argentina e Brasil foram 1,9 e 1,6 respectivamente. Tais números sinalizam claramente para uma participação muito pequena dos empregados no esforço de melhoria de desempenho.

\section{Objetivos de Melhorias}

Partindo de uma lista de 16 objetivos de melhoria, previamente selecionadas no questionário do IMSS, as empresas indicaram para qual deles haviam metas quantificadas de melhoria, assim como a importância de cada objetivo para a estratégia competitiva da empresa. A análise das respostas mostrou a existência de uma clara correlação entre a importância do objetivo e a existência de metas quantificadas de melhorias para aquele objetivo: quanto maior a importância, maior a percentagem de empresas com metas quantificadas de melhorias.

Na comparação entre os dois países, verificaram-se semelhanças e diferenças a respeito das melhorias. Considerando-se os 5 objetivos mais importantes em cada país, três eram comuns a ambos os países: melhorar a produtividade da mão de obra direta; reduzir os custos unitários; e reduzir o tempo de ciclo da produção. No entanto o mais importante objetivo para as empresas brasileiras, a redução dos níveis de estoque, não estava entre os objetivos mais importantes para as empresas argentinas. Por outro lado, o objetivo de melhorar a qualidade de conformação, que foi o mais quantificado e terceiro mais importante na Argentina, não consta como um objetivo importante no Brasil. Os objetivos de reduzir o número de fornecedores, reduzir os tempos de suprimento, e melhorar a qualidade dos fornecedores, todos relacionados ao desempenho na cadeia de suprimentos - um dos aspectos mais frágeis da manufatura 
brasileira - foram considerados bem mais importantes pelas empresas brasileiras do que pelas empresas argentinas.

Em ambos os países, as principais preocupações estavam relacionadas a dimensões de Custo e Tempo. Os objetivos relacionados à dimensão Qualidade, também foram considerados importantes em ambos os casos. No entanto as variáveis ligadas às dimensões de Inovatividade e Flexibilidade estavam entre aquelas consideradas menos importantes em ambos os países.

\section{As Atuais Práticas da Manufatura}

\section{Variáveis Hardware}

Os níveis de investimentos em equipamentos de processo nas empresas argentinas eram maiores do que nas empresas brasileiras; elas estavam investindo $13,3 \%$ da receita, em média, comparados com 9,6\% das empresas brasileiras. Tais investimentos pareciam estar mais direcionados para a aquisição de máquinas convencionais, para as quais as empresas argentinas possuíam uma maior proporção do que as empresas brasileiras; $91,7 \%$ versus $88,3 \%$ do total dos equipamentos. As empresas brasileiras faziam maior uso de equipamentos com controle numérico, numa proporção de $10,6 \%$ dos equipamentos, comparados com $4,1 \%$ na Argentina. No entanto as empresa argentinas eram maiores usuárias de centros de usinagem; 3,8\% versus $0,6 \%$ no Brasil. Em termos gerais, no entanto, os níveis de automação dos dois países eram equivalentes, se situando muito atrás dos níveis predominantes nos países mais desenvolvidos como a Alemanha, o Japão ou os EUA.

As empresa argentinas da amostra eram mais intensivas em capital do que as brasileiras: os números de empregados por máquina eram 2,8 e 8,1 respectivamente. Estes resultados devem ser analisados com cautela, pois podem ter sido influenciados, pelo menos em parte, pelas diferenças nos tipos de processos utilizados pelas empresas dos dois países.

\section{Variáveis Software}

Alguns aspectos organizacionais, em termos comparativos, devem ser ressaltados:

- Embora as empresas brasileiras se considerassem mais próximas dos seus fornecedores do que as argentinas, seu desempenho relacionado com aspectos de suprimento era bastante insatisfatório.

A organização da produção das empresas brasileiras era menos focada, pois 
tinham maior tendência de misturar, num mesmo equipamento, pequenas e grandes ordens de produção $(84,6 \%$ versus $71,1 \%)$.

- A amplitude de controle nas atividades de produção das empresas brasileiras era significativamente mais ampla do que nas argentinas: enquanto um supervisor no Brasil tinha 40 trabalhadores sob seu controle direto, na Argentina este número se reduzia para 20. Entretanto ambos apresentavam números semelhantes de níveis hierárquicos na produção. No que diz respeito ao número de classificações de funções, as empresas brasileiras possuíam 41, enquanto as argentinas trabalhavam com apenas 8 .

- Não existiam diferenças significativas entre os dois países no que diz respeito ao nível de utilização de trabalho em grupo (34\% da força de trabalho nas empresa brasileiras versus $31 \%$ nas empresas argentinas), ou de uso do método JIT para o recebimento de matérias primas e componentes (22\% nas empresas argentinas versus 19,6\% nas empresas brasileiras). O mesmo fato é verdadeiro para a proporção do uso de manutenção preventiva em relação à corretiva $(32,8 \%$ / 67,7\% no Brasil e 33,8\%/66,2\% na Argentina).

Considerados por alguns como a principal característica do novo paradigma da manufatura os aspectos sociais da manufatura podem ser comparados entre os dois países:

- As empresas brasileiras tinham menos flexibilidade em termos da força de trabalho, devido ao esquema de contratação da mão de obra; $88 \%$ dos empregados eram assalariados mensalistas, comparados com apenas $63 \%$ nas empresas argentinas.

- Incentivos salariais para os trabalhadores, baseados em alguma medida de produtividade, era prática adotada por $34 \%$ das empresas argentinas, em comparação com apenas $7 \%$ no Brasil.

- Enquanto as empresas brasileiras ofereciam mais horas de treinamento para os trabalhadores regulares (43 horas por ano, comparado com 33 horas por ano na Argentina), as empresas argentinas investiam mais no treinamento dos novos empregados (112 horas/ano, comparadas com 61 horas/ano nas empresas brasileiras).

- A programação da produção possuía um grau de centralização, no departamento de planejamento, equivalente nos dois países $(70,4 \%$ nas empresas brasileiras versus $71,1 \%$ nas empresas argentinas) 


\section{Adoção de Programas de Modernização}

Dentre os 27 programas de melhoria considerados na pesquisa do IMSS, os programas de Saúde e Segurança no Trabalho eram, de longe, aqueles com a maior taxa de adoção, tanto na Argentina quanto no Brasil, com valores correspondentes a $82 \%$ e $100 \%$ respectivamente. Estes programas eram também aqueles utilizados com maior intensidade por parte das empresas, e que geravam os maiores retornos.

Existiam dois outros programas coincidentes dentre os cinco mais adotados na Argentina e no Brasil - Definição de uma Estratégia de Manufatura (respectivamente 69\% e 95\%) e Controle Estatístico de Processo (respectivamente $76 \%$ e $91 \%)$.

Vale a pena lembrar que 3 dentre os 5 programas mais adotados na Argentina se relacionavam com a questão da qualidade - TQM, SPC, e QPD - versus apenas 1 no caso do Brasil - SPC. Os dois outros programas mais adotados no Brasil eram Análise de Valor e Abordagem de Trabalho em grupo.

As empresas brasileiras mostraram, em geral, melhor desempenho em termos de taxa de adoção, intensidade de uso, e retorno no uso dos 27 programas. Os maiores gaps que favoreciam as empresas brasileiras sobre as argentinas no que diz respeito à taxa de adoção eram nos programas de: KANBAN (59,7\%), DFM/ DFA (58,7\%), CAM (58,3\%), Engenharia Simultânea (53,4\%), e ISO 9000 $(46,0 \%)$.

Alguns programas de melhorias, apesar dos baixos índices de adoção, tanto no Brasil quanto na Argentina, resultaram em altos níveis de retorno, indicando portanto a possibilidade de virem a ser usados com maior intensidade no futuro próximo. Estes programas foram SMED, DFM/DFA, e CAM, tanto no Brasil quanto na Argentina; ABC e QFD no Brasil; e KANBAN e Engenharia Simultânea na Argentina. Os resultados alcançados por programas como SMED e CAM podem estar indicando que as empresas irão logo perceber a importância da introdução de flexibilidade nos seus sistemas produtivos.

\section{Melhorias de Desempenho}

Houve coincidência em quatro dos cinco indicadores de desempenho que apresentaram os maiores índices de melhorias na Argentina e no Brasil: qualidade de conformação, giro de estoque, entregas sem atraso, e serviço aos clientes. 
O quinto indicador na Argentina foi velocidade no desenvolvimento de produtos, e no Brasil foi prazo de entrega.

As taxas de melhorias nas empresas argentinas foram superiores às do Brasil em 10 dos 13 indicadores utilizados na pesquisa. Os maiores gaps de taxas de melhorias de desempenho em favor das empresas argentinas foram em relação ao market share (15,9\%); tempo de setup (14,1\%); variedade de produtos $(12,6 \%)$; velocidade no desenvolvimento de produtos (10,8\%); e custo unitário de fabricação (9,3\%). Os três indicadores onde o Brasil mostrou melhores índices de melhoria do que a Argentina, foram giro de estoque (16,6\%), qualidade de conformação $(11,3 \%)$, e prazo de entrega $(2,5 \%)$.

\section{Comentários Sobre Similaridades e Diferenças Na Manufatura}

Os dados sobre as estratégias, práticas e desempenhos que compõem a pesquisa do IMSS representam rico conjunto de informações relativas à situação recente da manufatura de produtos metálicos, máquinas, e equipamentos industriais de diversos países, inclusive Brasil e Argentina. Entretanto cuidados deveriam ser tomados quanto à interpretação dos dados, especialmente se se comparam dados relativos a países desenvolvidos e em desenvolvimento, devido às grandes diferenças de contexto.

É importante ter isto em mente sempre que se fizer esforço de comparação com base nos dados de Brasil e Argentina. Por exemplo, a maior participação dos custos externos de qualidade no total dos custos de qualidade, encontrado nas empresas brasileiras, pode ser indicação de que, ao invés de desempenho negativo, o que pode estar acontecendo é diminuição dos custos internos de qualidade em conseqüência da adoção de programas de qualidade. Outro exemplo pode ser a surpreendente alta percentagem de trabalhadores multiqualificados tanto na Argentina quanto no Brasil. Uma possível explicação é de que, por aceitar baixa qualificação e desempenho dos trabalhadores, fica mais fácil treinálos para diferentes funções; de fato, os números estariam indicando trabalhadores multifuncionais ao invés de trabalhadores multiqualificados. Portanto deverse-ia tomar o cuidado de colocar os resultados dentro dos seus devidos contextos, buscando explicações para situações que parecem anômalas ou surpreendentes.

Um exame das similaridades e diferenças nas informações relativas às empresa argentinas e brasileiras, na pesquisa do IMSS, deve partir da existência de pelo menos duas importantes razões explicativas, uma relacionada com as estru- 
turas e histórias do setor industrial em cada país, e outra relacionada ao ambiente econômico de cada país durante a fase de coleta de dados.

No conjunto das questões estruturais, o primeiro aspecto que cumpre considerar é o maior tamanho das empresas brasileiras. Isto parece ser função do maior tamanho da economia como um todo, mas pode também ser creditado à maior proporção de empresas que trabalham com a produção de produtos unitários de grande porte, como por exemplo navios. $\mathrm{O}$ grande e rápido crescimento da economia brasileira nos anos 60 e 70, parece ter criado uma base industrial maior e mais diversificada, que se reflete nas empresas que estão sendo analisadas. As diferenças entre empresas nos dois países parecem persistir nos dias de hoje, apesar dos altos níveis de concentração e integração vertical verificados no caso das empresas argentinas, como discutido anteriormente.

Existem de fato indicações de maior número de competidores importantes nas industrias metalmecânicas no Brasil, como bem indicam os menores graus de concentração industrial medidos pela participação de mercado dos principais atores. As empresas argentinas, por outro lado, tendem a ter maior grau de integração vertical do que as empresas brasileiras, provavelmente como conseqüência do processo de absorção pelas maiores empresas, dos seus fornecedores de menor porte, que tiveram dificuldades de sobreviver à severa recessão dos anos 70 e 80 . As empresas brasileiras tendem a ser mais orientadas para a exportação, especialmente para outras áreas econômicas que não a América do Sul, do que as empresa argentinas.

Apesar da aparente superioridade das empresas brasileiras no que se refere à estrutura de manufatura, empresas de ambos os países parecem estar defasadas em relação aos países desenvolvidos quanto aos avanços na direção de maiores níveis de automação e de tecnologias flexíveis (com diferenças muito pequenas em favor do Brasil).

Existem alguns aspectos chaves que precisam ser considerados, em termos das condições dos ambientes econômicos na Argentina e no Brasil, na época da realização da pesquisa de campo. Ambos os países vinham de um longo período de recessão combinada com alta inflação. A longa recessão parece ter tido maior impacto na indústria argentina do que na brasileira, resultando em maior número de fechamento de empresas e em condições mais desfavoráveis de competitividade na implementação do plano de estabilização em 1991. Entretanto o processo argentino na direção das mudanças de rumo na política econômica se iniciou primeiro; o país estava muito à frente do Brasil em termos de estabilização, beneficiando-se portanto de clima econômico mais favorável para investimentos. Apesar da política de liberalização econômica ter sido iniciada no Brasil em 1990, foi apenas em 1994 que as incertezas no ambiente econô- 
mico diminuíram em resposta a um plano sério de estabilização da moeda, similar em alguns aspectos àquele previamente implementado na Argentina.

Torna-se portanto possível identificar dois momentos distintos em termos da influência do ambiente econômico nas empresas dos dois países na época da pesquisa de campo; enquanto as empresa argentinas estavam trabalhando em condições de muito maior confiança, com claras perspectivas sobre o desempenho da economia, as empresas brasileiras sofriam pressões concorrenciais vindas de dentro e de fora do país, enquanto tinham de lidar com as ameaças e problemas da alta inflação, em clima de baixas expectativas sobre a economia. Considera-se aqui que as semelhanças e diferenças nas características, na posição e desempenho, discutidas nas seções anteriores, podem ser relacionadas com tais questões.

A maior concentração industrial na Argentina pode ser o resultado combinado das condições presentes e passadas - a sobrevivência dos mais fortes e a busca por maiores escalas, através de processos de fusões e incorporações, que envolvem especialmente capitais estrangeiros (característica da indústria brasileira nos anos 70).

A aparente tendência de se utilizarem mais de sistemas de produção, baseados em previsão de vendas, do que por encomendas firmes dos clientes, no caso da Argentina, pode estar relacionado com a forte integração entre marketing e produção, como conseqüência de maior estabilidade na economia; mas fatores estruturais, principalmente maior incidência de produção tipo projeto nas empresas brasileiras da amostra, podem também ser responsáveis pelas diferenças encontradas.

A análise dos resultados, em termos de desempenhos operacionais, de objetivos, de esforços de melhoria e ganhos reais aponta para as principais preocupações de cada um dos países. Porter (1990) já havia chamado a atenção para o fato de que as empresas tendem a agir mais na direção de minimizar os efeitos das ameaças sobre os pontos fracos do que de reforçar os pontos fortes no sentido de aproveitar as oportunidades, ou seja, o medo do fracasso é maior do que a esperança do sucesso. Os resultados deste estudo parecem confirmar este ponto.

Os pontos mais fracos das empresas brasileiras podem ser encontrados no gerenciamento dos canais de suprimento. $\mathrm{O}$ número de fornecedores pode ser considerado muito alto, e os tempos de entrega são muito superiores aos patamares internacionais e aos das empresas argentinas. Embora os tempos de entrega mais longos possam ser em parte imputados à maior incidência do sistema de produção por projeto, as desvantagens ainda permanecem, mesmo quando se consideram apenas os casos de produção em lotes e em linha. As empresas bra- 
sileiras possuem menos recebimentos no sistema just-in-time, e atribuem à falta de materiais a metade dos atrasos na entrega dos produtos. Elas possuem também menor flexibilidade a variações de volume, pois estão menos inclinadas a manter "colchão" de capacidade.

Por outro lado, as empresas brasileiras tendem a ser mais eficientes no uso de seus recursos. As empresas competem principalmente com base em preços, e as pressões recentes do ambiente econômico as tem levado a grande esforço no sentido da redução de custos via programas de qualidade e de eliminação de desperdícios. As condições adversas para os investimentos reforçaram ainda mais esta tendência, que fica implícita na tentativa de utilização máxima da capacidade instalada. As empresa brasileiras conseguiam maior giro de estoques e eficiência produtiva. Elas também fazem melhor uso dos recursos humanos, que pode ser comprovado pelo menor absenteísmo e rotatividade de pessoal.

As empresas argentinas também procuravam competir com base em dimensões mais básicas, ou seja, preço e qualidade. Mas as condições econômicas favoreceram muito mais os investimentos em ativos (hardware) e recursos humanos. Entretanto os investimentos até o momento da pesquisa não haviam sido suficientes para mudar a base tecnológica do processo na indústria, na direção de mais automação, talvez devido ao excesso de variedade de produtos ainda existente e à falta de escala adequada.

As empresa argentinas estão aparentemente à frente do Brasil no que diz respeito à flexibilização das relações trabalhistas: possuem maior proporção de empregados trabalhando em tempo parcial, e utilizam número muito menor de classificações de funções. No que diz respeito aos aspectos sociais na produção, os dois países parecem ser equivalentes, embora as empresas argentinas tendam a fazer maior uso de sistemas de incentivos salariais e darem mais horas de treinamento aos novos empregados.

Os movimentos de qualidade começaram mais cedo no Brasil, fazendo com que as empresas adotassem programas japoneses de gestão que resultaram em consideráveis melhorias de desempenho naquela dimensão. As questões de qualidade no Brasil eram muito menos problemáticas do que as questões de desempenho nos canais de suprimento. Portanto não foi nenhuma surpresa a constatação de que as metas prioritárias para melhorias nas empresas brasileiras estivessem relacionadas à redução de estoques. Além de estar diretamente relacionada com os problemas da cadeia de suprimento, a redução de estoques tinha muito sentido numa economia dominada por alta inflação e elevados custos financeiros. As empresas argentinas, por outro lado, pareciam estar mais atrasadas nos esforços por qualidade, mas com menos dificuldades no que diz respeito aos problemas 
na cadeia de suprimentos, em parte devido a seu maior nível de integração vertical.

As questões de variedade e desenvolvimento de novos produtos pareciam problema ainda não resolvido em ambos os países (embora com melhores perspectivas na Argentina), devido principalmente à baixa capacitação tecnológica endógena.

Estas prioridades foram explicitadas nas metas de melhorias formalmente estabelecidas, assim como na adoção dos programas de modernização pelas empresa de ambos os países. As metas mais importantes, no Brasil, estavam relacionadas com custos e tempos; no caso da Argentina, além de custos e tempos, também a qualidade era meta altamente prioritária. Em termos de adoção de programas de modernização, no caso do Brasil, apenas um programa de qualidade estava relacionado entre os cinco mais adotados; no caso da Argentina, três programas de qualidade estavam relacionados entre os cinco mais adotados.

É importante ressaltar que em ambos os países os programas de "saúde e segurança no trabalho" figuravam em primeiro lugar em termos de adoção, assim como de retorno para as empresas. Este talvez seja um resultado típico de países em desenvolvimento, onde as políticas no sentido de melhorar a qualidade de vida dos trabalhadores oferecem enormes potenciais de retorno, devido ao baixo índice de qualidade de vida e ao enorme potencial de aumento de produtividade.

As empresas argentinas estavam conseguindo melhores índices de melhoria de desempenho do que as brasileiras. Embora o clima econômico mais favorável na Argentina em 1993 deva ter contribuído, pelo menos em parte, para este avanço mais rápido, outra explicação plausível é de que na Argentina as empresas partiram de uma base inferior de desempenho, tornando mais fácil os ganhos mais rápidos. Qualquer que seja a explicação, o fato concreto é que as empresas argentinas estavam avançando mais rapidamente que as brasileiras nos dois anos anteriores à data da realização da pesquisa.

\section{CONCLUSÕES}

Não existe trajetória única para a modernização total da manufatura, ou seja, que envolva mudanças na tecnologia de processo, nos sistemas operacionais, nas práticas produtivas e gerenciais e na organização da força de trabalho. Na verdade as empresas podem optar pela trajetória tecnológica (mudanças no hardware), ou pela trajetória funcional (mudanças prioritariamente no software), como forma preferencial de alcançar a modernização total (Abranches et al., 1994). 
Os resultados da pesquisa do IMSS e a comparação entre os dados das empresas brasileiras e argentinas da amostra levam a algumas indicações sobre as trajetórias preferenciais de modernização adotadas pelas empresas dos dois países. As empresas brasileiras estavam aparentemente se movendo ao longo da trajetória soft de modernização, com ênfase nas prática identificadas com o modelo de lean production - atenção voltada principalmente para as questões de qualidade e redução de desperdícios. As empresas argentinas, por outro lado, estavam aparentemente se movendo numa direção similar, mas adicionando a isto esforços no sentido da modernização do hardware, como bem indicam seu planos mais ambiciosos de investimentos em novos equipamentos.

Estas tendências mais gerais podem ser relacionadas com as questões estruturais e ambientais discutidas anteriormente. Os diferentes pontos de partida, condicionados pelas histórias de desenvolvimento da indústria local, parecem ter sido responsáveis pelas diferentes escolhas gerenciais no caminho da modernização industrial. O melhor clima econômico na Argentina permitiu às suas empresas perseguir políticas de modernização que envolviam tanto as questões de software, com maior ênfase nos aspectos da qualidade, quanto as questões de hardware, em termos da adoção de equipamentos mais novos e mais modernos. No Brasil, por outro lado, as condições econômicas ainda não favoreciam os investimentos de capital; as empresas estavam lutando por maior competitividade mediante o enxugamento das operações na busca por maior eficiência e velocidade de resposta.

Com isso era de se esperar que as empresas brasileiras viessem a complementar seu esforço no caminho da modernização, por meio de investimentos em hardware, uma vez que o ambiente econômico mostrasse sinais de recuperação no nível de atividade e na estabilidade da moeda. Os primeiros sinais, após a implementação do Plano Real, com base em informações não sistematizadas, tendem a confirmar esta expectativa. Futuras pesquisas poderão indicar se, de fato, a opção anterior pela trajetória do software foi condicionada pelas restrições do ambiente, ou foi simplesmente reflexo das limitações tecnológicas e gerenciais das empresas brasileiras. Este é também o caso no que diz respeito à reação das empresas às recentes dificuldade econômicas observadas na Argentina.

Em ambos os países existem, no entanto, duas questões da maior importância que merecem maior atenção governamental e gerencial, ou seja, a qualidade técnica da força de trabalho e a maior contribuição dos empregados no processo de melhorias permanentes. Os modestos avanços ocorridos nos aspectos sociais da manufatura representam sério obstáculo ao aumento da competitividade das empresas. A dificuldade em competir com base na flexibilidade e inovatividade, 
duas claras tendências dos mercados internacionais, talvez seja o maior desafio para ser enfrentado pelas empresas argentinas e brasileiras na sua luta para alcançar competitividade internacional sustentada.

Not A S

\footnotetext{
* Os autores gostariam de agradecer a colaboração de Marcelo Paladino, Roberto Luchi, e Eduardo Remolins, do IAE de Buenos Aires, Argentina, pelos dados sobre o ambiente econômico e estratégias de manufatura na Argentina, assim como pelas discussões que conduziram sobre várias das questões levantadas no texto.

${ }^{1}$ O IMSS - International Manufacturing Strategy Survey - é um esforço de pesquisa cooperativa desenvolvido a partir da iniciativa conjunta dos Professores Chris Voss, da London Business School, Inglaterra, e Per Lindberg, da Chalmers University, Suécia. No Brasil ela foi conduzida pelo COPPEAD/ UFRJ.

${ }^{2}$ Ver por exemplo Womack et al. (1990) para uma comparação entre entre o antigo sistema de produção de massa, e o novo - produção enxuta.

${ }^{3}$ Os dados nesta seção, a não ser em casos específicos indicados, foram retirados do relatório do IMD World Competitiveness Report 1993, que contém dados estatísticos assim como opinião de executivos sobre vários aspectos estruturais e do ambiente econômico de cada país.

${ }^{4}$ De fato o Brasil era o único dentre os quatro maiores países latino americanos (os outros: Argentina, México e Chile) a ter uma balança comercial positiva.

${ }^{5}$ Números de 1992.
}

REFERÊNCIAS BIBLIOGRÁFICAS

ABRANCHES, S. et al.

O novo contexto da competição internacional e o posicionamento do Brasil. Rio de Janeiro: Finep, 1994. Documento de Trabalho n. 1.

IMD.

\section{World Competitiveness Report}

1993. Lausanne, Suissa, 1994.
PORTER, M. E.

The competitive advantage of nations. New York: Free Press, 1990.

WOMACK, J. P. et al.

The machine that changed the world. MIT Press, 1990. 